\title{
Computational Study and Biological Evaluation of Isolated Saponins from the Fruits of Gleditsia aquatica and Gleditsia caspica
}

\author{
Ehab A. Ragab $\oplus^{1}$, Usama Shaheen $\oplus^{1,2}$, Ammar Bader $\odot^{2}$, \\ Khaled M. Elokely $\oplus^{3,4,5^{*}}$ and Mohammed M. Ghoneim $\odot{ }^{1,6^{*}}$ \\ ${ }^{1}$ Department of Pharmacognosy, Faculty of Pharmacy, Al-Azhar University, Cairo, 11371, Egypt \\ ${ }^{2}$ Department of Pharmacognosy, Faculty of Pharmacy, Umm Al-Qura University, Makkah, 21955, \\ Saudi Arabia \\ ${ }^{3}$ Department of Pharmaceutical Chemistry, Faculty of Pharmacy, Tanta University, Tanta 31527, \\ Egypt \\ ${ }^{4}$ Institute for Computational Molecular Science (ICMS), Temple University, Philadelphia, PA 19122, \\ USA \\ ${ }^{5}$ Arnold and Marie Schwartz College of Pharmacy and Health Sciences, Division of Pharmaceutical \\ Sciences, Long Island University, Brooklyn, New York 11201, USA \\ ${ }^{6}$ Department of Pharmacy, College of Pharmacy, Al Maarefa University, Riyadh, Saudi \\ Arabia
}

(Received August 07, 2020; Revised October 09, 2020; Accepted October 10, 2020)

\begin{abstract}
Phytochemical study of the ethanolic extract of the fruits of Gleditsia aquatica and Gleditsia caspica resulted in the isolation of the triterpene saponins; aquaticasaponin A (1), aquaticasaponin B (2), caspicaoside L (3) and caspicaoside M (4). Compound (1) showed good activity against methicillin resistant Staphylococcus aureus (MRSA) $\left(\mathrm{IC}_{50}=16.3 \mu \mathrm{g} / \mathrm{mL}\right)$ and Staphylococcus aureus (non-MRSA), $\left(\mathrm{IC}_{50}=12.2 \mu \mathrm{g} / \mathrm{mL}\right.$ ) and it expressed considerable cytotoxic activity against BT-549 (Human Ductal Carcinoma, Breast), KB (Human Epidermal Carcinoma, Oral) and SK-MEL (Human Malignant Melanoma) with IC $_{50}$ values of 8.3, 10.0 and 3.3 $\mu \mathrm{g} / \mathrm{mL}$, respectively. Compounds (2) and (3) showed potent cytotoxicity against BT-549 with $\mathrm{IC}_{50}$ values of 5.3 and $7.3 \mu \mathrm{g} / \mathrm{mL}$, and against SK-MEL with $\mathrm{IC}_{50}$ values of 4.3 and $3.1 \mu \mathrm{g} / \mathrm{mL}$, respectively. Compound (4) showed good cytotoxicity against $\mathrm{KB}$ with $\mathrm{IC}_{50}$ value of $7.3 \mu \mathrm{g} / \mathrm{mL}$. In consistent, the study of molecular determinates of cytotoxic activity of these new scaffolds showed close high docking scores to CD81 (Cluster of Differentiation 81) human antigen which could be of great importance for the development of new cytotoxic candidates. The structure identification of isolated metabolites was carried out using 1D and 2D NMR and mass spectra.
\end{abstract}

Keywords: Triterpenoidal saponins; cytotoxicity; CD81 human antigen; computational study; MRSA. (C) 2020 ACG Publications. All rights reserved.

${ }^{*}$ Corresponding author: E- Mail: khaled.elokely@liu.edu (KME) and mghoneim@ mcst.edu.sa (MMG), Phone $+966-537415011$. 


\section{Plant Source}

The fruits of Gleditsia aquatica March. were collected from Agricultural Museum, Dokki, Giza, Egypt in March 2001 and the fruits of Gleditsia caspica Desf. were collected from Al-Orman Garden, Giza, Egypt in April 2014. Both fruits were kindly identified by Badeia Hassan Aly Dewan, Consultant of Egyptian Flora, Agricultural Museum, Dokki, Giza, Egypt, and by Mrs. Terase Labib, Taxonomist of Al-Orman Garden, Giza, Egypt. Voucher specimens [herbarium No. G-01 for G. aquatica and herbarium No. G-02 for G. capsica] has been deposited in the Pharmacognosy Department, Faculty of Pharmacy, Al-Azhar University, Cairo, Egypt.

\section{Previous Studies}

Genus Gleditsia (Fabaceae) are well known due to a wide range of biological activities [1]. The constituents and activities of the major species of Gleditsia have been reported; a literature survey indicates, triterpenoidal saponins [2-6]. Gleditsia aquatica March. and Gleditsia caspica Desf are perennial shrubs or trees distributed throughout Egypt for ornamental purpose. The cytotoxic activity of the triterpenoid saponins isolated from the fruits of genus Gleditsia against different cell lines was previously reported [2]. In our previous studies we reported the antimicrobial and cytotoxic activity of aquaticasaponins A and B isolated from Gleditsia aquatica [3] and the cytotoxic activity of caspicaosides L and M isolated from Gleditsia caspica [4]. Aquaticasaponins A and B showed the highest degree of antimicrobial activity against Syncephalastrum racemosum and Escherichia coli, respectively and were exhibited good cytotoxic activity against human breast cancer (MCF-7) and human colon cancer (HCT-116) cell lines. Furthermore, caspicaosides L and M showed variable cytotoxic activity against human breast adenocarcinoma (MCF 7), human ovary adenocarcinoma (A2780) and human colon adenocarcinoma (HT 29) cancer cell lines. Caspicaosides L and M were selective against the normal fibroblast MRC 5. In continuation of our effort to search for metabolites against both methicillin resistant Staphylococcus aureus (MRSA) and cytotoxic compounds [7, 8]. The aim of this study is to extent the investigation on the antimicrobial and cytotoxic activity of metabolites isolated from Gleditsia aquatica and Gleditsia caspica and to perform a molecular docking of these metabolites. Isolated metabolites from Gleditsia aquatica and Gleditsia caspica showed good activity against both methicillin resistant Staphylococcus aureus (MRSA) and different human cancer cell lines. In addition, the aglycon component of aquaticasaponin A, echinocystic acid, is reported to bind to CD81 (Cluster of Differentiation 81) human antigen [9] with Kd of $21 \mathrm{nM}$. Increased expression of CD81 is linked with poor prognosis, increased progression and cellular migration of several cancers including breast and prostate cancers $[10,11]$. The effect of CD81 on tumor growth and cancerous cells' migration may be attributed to the function modulation leading to increase in the number of myeloid-derived suppressor cells and T-regulatory cells [12].

\section{Present Study}

Using combined chromatographic methods, the ethanolic extract of the fruits of Gleditsia aquatica and Gleditsia caspica resulted in the isolation of the triterpenoidal saponins; aquaticasaponins A (1) and B (2) from the fruits of Gleditsia aquatica and the triterpenoidal saponins caspicaosides L (3) and M (4) from the fruits of Gleditsia caspica (Figure 1). The structures of these compounds were determined using a combination of $1 \mathrm{D}\left({ }^{1} \mathrm{H},{ }^{13} \mathrm{C}\right.$, DEPT) and 2D (DQF-COSY, HMQC, HSQC, TOCSY, $\left.{ }^{1} \mathrm{H}^{-13} \mathrm{C}-\mathrm{HSQC}-\mathrm{TOCSY}, \mathrm{HMBC}, \mathrm{ROESY}, \mathrm{NOESY}\right) \mathrm{NMR}$ experiments and HRESIMS analysis. Compound $\mathbf{1}$ showed good activity against methicillin resistant Staphylococcus aureus (MRSA) with $\mathrm{IC}_{50}$ value of $16.3 \mu \mathrm{g} / \mathrm{mL}$. They also exhibit activity against Staphylococcus aureus (non-MRSA) with $\mathrm{IC}_{50}$ value of $12.2 \mu \mathrm{g} / \mathrm{mL}$. Compound 1 exhibited high cytotoxic activity against BT-549 (Human Ductal Carcinoma, Breast), KB (Human Epidermal Carcinoma, Oral) and SK-MEL (Human Malignant Melanoma) with $\mathrm{IC}_{50}$ values of $8.3,10.0$ and $3.3 \mu \mathrm{g} / \mathrm{mL}$, respectively. 
Compounds 2 and 3 showed potent cytotoxicity against BT-549 with $\mathrm{IC}_{50}$ values of 5.3 and 7.3 $\mu \mathrm{g} / \mathrm{mL}$, respectively and against SK-MEL with $\mathrm{IC}_{50}$ values of 4.3 and $3.1 \mu \mathrm{g} / \mathrm{mL}$, respectively. Compound 4 revealed good cytotoxicity against $\mathrm{KB}$ with $\mathrm{IC}_{50}$ value of $7.3 \mu \mathrm{g} / \mathrm{mL}$ (Table 1). The tested compounds 1-4 were found to be devoid of cytotoxicity against mammalian cells.
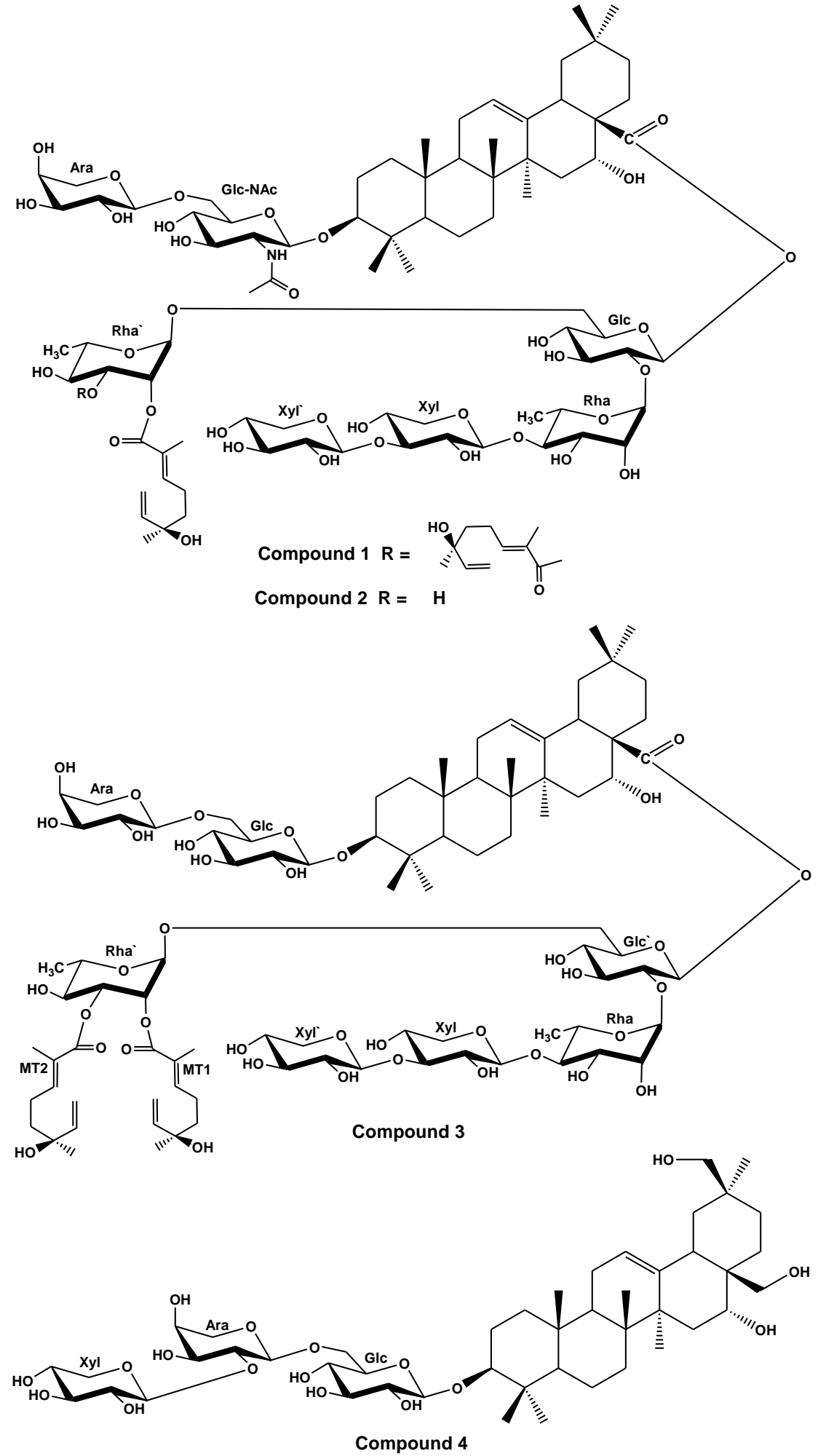

Figure 1. Chemical structures of compounds 1-4 
The cholesterol binding site was considered the ligand pocket in this docking experiment due to the high structural similarity between the aglycon moieties and cholesterol. We did not perform a retrospective docking study. The binding site is wide and may allow for fitting of considerable big molecules. The ligands docked (Figure 2) with high and very similar docking scores of $-7.4 \mathrm{kcal} / \mathrm{mol}$ and $-7.2 \mathrm{kcal} / \mathrm{mol}$. Both ligands and cholesterol showed a strong hydrogen bond with Glu219. The ligands showed hydrophobic and van der Waals contacts with several amino acids in the binding site including Ph17, Asn18, Phe21, Val68, Val71, Met72, Val75 Gly76, Phe94, Leu98, Leu101, Glu105, Val212, Ile215 and Met216. Considering chemical complementarities, the chemistry of the ligands is compatible with that of the receptor, which explains the high binding affinity. The conformational lock of the ligand with reduced number of rotatable bonds, allowed the structures to adopt bioactivelike conformer which is very close to cholesterol in the active site. There are rooms for structural modifications to improve ligand interaction to the target, particularly in place of the sugar portion, however, we must keep the conformational lock and chemical complementarities with the target.

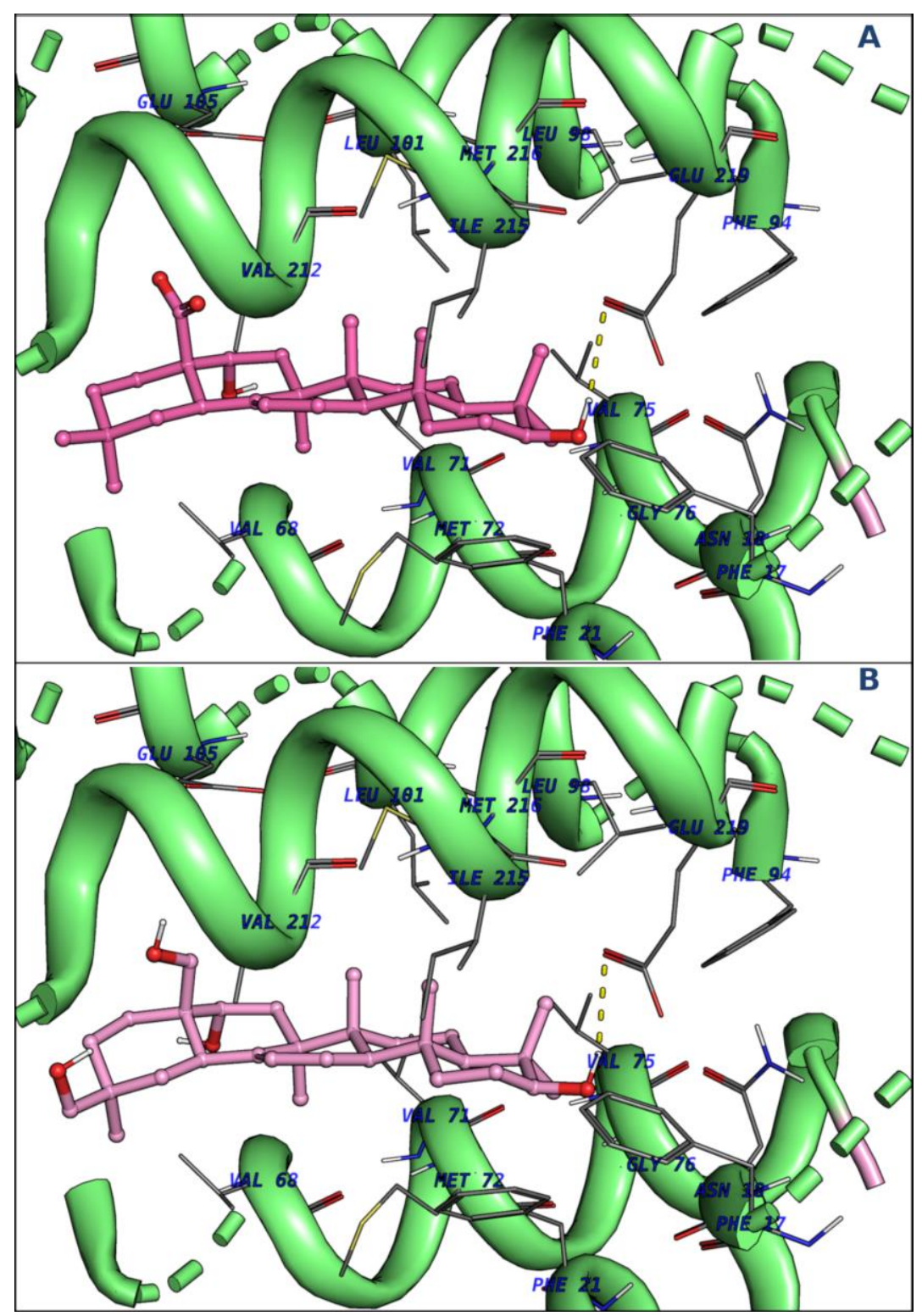

Figure 2. Binding simulations of echinocystic acid (A) and erythrodiol (B) showing the interacting amino acids. 
Table 1. Cytotoxic activity of isolated metabolites (Highest test concentration $10 \mu \mathrm{g} / \mathrm{mL}$ )

\begin{tabular}{ccccccc}
\hline & \multicolumn{7}{c}{ IC $_{\mathbf{5 0}}$ in $\boldsymbol{\mu g} / \mathbf{m L}$} \\
Compound & BT-549 & KB & SK-MEL & SK-OV-3 & VERO & LLC-PK11 \\
\hline 1 & 8.3 & 10 & 3.3 & NA & NA & NA \\
2 & 5.3 & NA & 4.3 & NA & NA & NA \\
3 & 7.3 & NA & 3.1 & NA & NA & NA \\
4 & NA & 7.3 & NA & NA & NA & NA \\
Doxorubicin & 1.3 & 1.5 & 1.2 & 1.6 & $>5$ & 0.5 \\
\hline
\end{tabular}

$\mathrm{NA}=$ Not active up to the maximum dose tested $10 \mu \mathrm{g} / \mathrm{mL}$. cell lines; skin melanoma (SK-MEL), epidermal carcinoma (KB), breast carcinoma (BT-549), ovarian carcinoma (SKOV-3) and two non-cancerous kidney cell lines (LLC-PK11 and Vero).

\section{Acknowledgments}

The authors would like to thank the AlMaarefa University for financial support given for this research and thankful for the support from Faculty of Pharmacy, Al-Azhar University.

\section{Supporting Information}

Supporting Information accompanies this paper on http://www.acgpubs.org/journal/recordsof-natural-products

\section{ORCID}

Ehab A. Ragab: 0000-0002-4011-7233

Usama Shaheen: 0000-0002-2970-8964

Ammar Bader: 0000-0003-2201-7201

Khaled M. Elokely: 0000-0002-2394-021X

Mohammed M. Ghoneim: 0000-0002-9179-4373

\section{References}

[1] Y. Zhong and D.C. Dian (1977). Jiangsu new medical college. Shanghai People's Public Heal. Publ. House Shanghai, pp. 1144-1147.

[2] J.P. Zhang, X.H. Tian, Y.X. Yang, Q.X. Liu, Q. Wang, L.P. Chen, H.L. Li and W.D. Zhang (2016). Gleditsia species: an ethnomedical, phytochemical and pharmacological review, J. Ethnopharmcol. 178, $155-171$.

[3] E.A. Ragab (2015). New antimicrobial and cytotoxic acylated triterpenoidal saponins from Gleditsia aquatica, Med. Chem. Res. 24, 2916-2925.

[4] U. Shaheen, E.A. Ragab, A.N. Abdalla and A. Bader (2018). Triterpenoidal saponins from the fruits of Gleditsia caspica with proapoptotic properties, Phytochemistry 145, 168-178.

[5] E.A. Ragab, M. Hosny, H.A. Kadry and H.A. Ammar (2010). Acylated triterpenoidal saponins and cytokinins from Gleditsia aquatica, J. Pharmacog. Phytother. 2, 24-33.

[6] F. Melek, I. Kassem, T. Miyase and W. Fayad (2014). Caspicaosides E-K, triterpenoid saponins and cytotoxic acylated saponins from fruits of Gleditsia caspica Desf, Phytochemistry 100, 110-119.

[7] M.M. Ghoneim, K.M. Elokely, A. Atef, A.-E.I. Mohammad, M. Jacob, M.M. Radwan, R.J. Doerksen, S.J. Cutler and S.A. Ross (2014). Asphodosides A-E, anti-MRSA metabolites from Asphodelus microcarpus, Phytochemistry 105, 79-84. 
[8] M.M. Ghoneim, A. Musa, A.A. El-Hela and K.M. Elokely (2018). Evaluation and understanding the molecular basis of the antimethicillin-resistant Staphylococcus aureus activity of secondary metabolites isolated from Lamium amplexicaule, Pharmacognosy Mag. 14, 3-7.

[9] F. Yu, Q. Wang, Z. Zhang, Y. Peng, Y. Qiu, Y. Shi, Y. Zheng, S. Xiao, H. Wang and X. Huang (2013). Development of oleanane-type triterpenes as a new class of HCV entry inhibitors, J. Med. Chem. 56, 4300-4319.

[10] N. Zhang, L. Zuo, H. Zheng, G. Li and X. Hu (2018). Increased expression of CD81 in breast cancer tissue is associated with reduced patient prognosis and increased cell migration and proliferation in MDA-MB-231 and MDA-MB-435S human breast cancer cell lines in vitro, Med. Sci. Monit. 24, 57395747.

[11] Y. Zhang, H. Qian, A. Xu and G. Yang (2020). Increased expression of CD81 is associated with poor prognosis of prostate cancer and increases the progression of prostate cancer cells in vitro, Exp. Ther. Med. 19, 755-761.

[12] F. Vences-Catalán, R. Rajapaksa, M.K. Srivastava, A. Marabelle, C.C. Kuo, R. Levy and S. Levy (2015). Tetraspanin CD81 promotes tumor growth and metastasis by modulating the functions of $\mathrm{T}$ regulatory and myeloid-derived suppressor cells, Cancer Res. 75, 4517-4526.

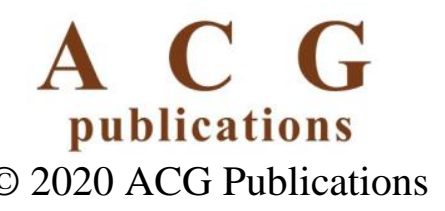

